\title{
Quem Precisa de São Nabuco?
}

\author{
Celia Maria Marinho de Azevedo
}

\section{Resumo}

A partir de uma leitura retrospectiva e crítica do político e abolicionista Joaquim Nabuco, o artigo tenta "descanonizar" as imagens tradicionais produzidas sobre ele ao longo da historiografia clássica. Desde resenhas de livros do autor, até repercussōes na mídia sobre sua obra, a autora procura reler a obra e a vida de Joaquim Nabuco a partir de uma interpretação que visa respeitar o contexto em que esta foi feita. Analisa artigos sobre Nabuco de historiadores contemporâneos em jornais para criticar a tentativa acadêmica de transformar o abolicionista Nabuco em uma espécie de santo protetor dos escravos. A autora argumenta que mesmo defendo uma causa aparentemente justa para a época, Nabuco não estava livre dos estereótipos e do racismo típicos de seu tempo em relação aos negros.

Palavras-chave: Joaquim Nabuco; São Nabuco; historiografia; abolicionismo. 
Celia Maria Marinho de Azevedo

\begin{abstract}
Who Needs St. Nabuco?

This article is based on the author's critical retrospective study of the life and works of Joaquim Nabuco, a politician and abolitionist. She attempts to reinterpret the traditional picture presented in classical historical biographies after having perused reviews of his books and analyzed the repercussion of his work in the media. Her interpretation is in tune with the context of his times. She analyzes newspaper articles on Nabuco written by contemporary historians and criticizes academic endeavors to show abolitionist Nabuco as a kind of sainted protector of slaves. The author maintains that even when he advocated a cause apparently just in his days, Nabuco was not averse to stereotyping and to the then typical racism ostracizing Negroes.
\end{abstract}

Keywords: Joaquim Nabuco; St. Nabuco; historiography; abolitionism.

\title{
Résumé
}

\section{Qui a Besoin de Saint Nabuco?}

À partir d'une relecture critique des écrits sur le politicien et abolitionniste Joaquim Nabuco, l'auteur essaie de désacraliser les images traditionnelles faites sur lui dans l'historiographie classique. Des recensions de livres de l'auteur aux articles parus dans les média sur son oeuvre, l'auteur fait une relecture de Nabuco selon une interprétation qui vise à respecter le contexte où il a vécu. Elle analyse donc des articles de journaux écrits par des historiens contemporains tout en dénonçant leur tentative de transformer cet abolitionniste dans une sorte de saint protecteur des esclaves. Elle montre que, bien que défenseur d'une cause apparemment juste à l'époque, Nabuco n'a pas échappé aux stéréotypes sur les Noirs et au racisme dominant à l'époque.

Mots-clé: Joaquim Nabuco; São Nabuco; historiographie; abolitionnisme.

Estudos Afro-Asiáticos, Ano 23, no 1, 2001, pp. 86-97 
$\mathbf{P}$ oucos personagens da História do Brasil, definidos como heróis em algum tempo, conseguiram resistir à ação corrosiva e maléfica do tempo. José Bonifácio, o nosso augusto "Patriarca da Independência", D. Pedro I com seu grito viril de "Independência ou Morte", Duque de Caxias, o salvador da pátria contra os "selvagens paraguaios", Princesa Isabel, a "Redentora" dos infelizes e incapazes escravos, e até mesmo Tiradentes, o mártir da Inconfidência, já foram tirados convenientemente de seus pedestais e devolvidos à condição de humanos.

Há, porém, um herói que parece resistir a qualquer ação do tempo, tal a longevidade da sua celebração tanto em surrados compêndios escolares como em textos clássicos ou recentes de alguns dos nossos mais renomados historiadores. Mas, não se trata de um simples herói cuja figura remota nos inspira a crença na possibilidade de homens públicos íntegros e devotados ao bem geral da nação. Sua celebração tem sido tamanha, as evocações em seu nome têm sido tão incessantes e apaixonadas, que alguém que não reconheça tal culto, ou não compartilhe de uma tal devoção, tem a sensação de estar sendo arrastado a um ritual sufocante de rezas e incenso, fora do qual só existiriam as fogueiras inquisitoriais. Portanto, o mais certo, e mais conveniente, será chamá-lo de Santo. Em vez de Joaquim Nabuco, diremos, simplesmente, São Nabuco. E assim, sua canonização será límpida e completa. ${ }^{1}$

O processo de canonização de Joaquim Nabuco é bem antigo em nossa historiografia. Como não há um papa a presidir, é preciso visualizar a construção de São Nabuco em diversos momentos e gêneros discursivos - biografias, memórias, narrativas da Abolição, discursos comemorativos, artigos de imprensa, livros didáticos, prefácios e resenhas de seus livros -, escritos inicialmente por amigos e admiradores, entre eles sua filha, Carolina Nabuco, e, posteriormente, por discípulos e admiradores.

Estudos Afro-Asiáticos, Ano 23, no 1, 2001, pp. 87-97 
Houve ainda a ajuda inestimável do próprio Nabuco na construção de sua memória. Em seu livro Minha Formação, escrito nos últimos anos do século XIX, ele nos legou uma espécie de testamento político de um liberal monarquista que, passado o primeiro susto, soube entrar no novo século de cabeça erguida e em busca do que fazer. A diplomacia abriu-lhe as portas e o monarquista serviu à República com fidelidade animal, até morrer, em 1910. Aviso aos guardiães de São Nabuco: não há, nesta última imagem - fidelidade animal - nenhuma heresia. Sirvo-me aqui de uma imagem delineada por ele mesmo ao rememorar, com saudades, o servilismo de seus queridos escravos, já perdidos para todo e sempre, nos seus bons tempos de criança no Engenho Massangana. Diz o Santo: "Deus conservara ali o coração do escravo, como o do animal fiel, longe do contacto com tudo que o pudesse revoltar contra a sua dedicação" (Nabuco, 1963:191-2).

Não reconstruirei aqui, passo a passo, a trajetória da sua canonização, pois já tenho em mãos dois artigos, publicados recentemente, e que reafirmam, em uníssono, no alvorecer deste novo século, os cânones associados, de longa data, à figura de Nabuco. Em um espaço de um mês, o caderno "Mais" da Folha de S. Paulo nos brindou com um artigo de Evaldo Cabral de Mello, "Reler o Abolicionismo" (27/2/2000), e outro de José Murilo de Carvalho, "Saudade do Escravo" (2/4/2000). São, como sabemos, dois historiadores muito respeitados, autores de contribuições substanciais para a historiografia brasileira. Entretanto, para o meu pesar, eles colaboram para dar vida nova ao Santo, tal a solicitude com que tentam livrá-lo da possibilidade de que novos e incautos leitores - porventura já envenenados pelo chamado espírito do "politicamente correto" - se espantem com a linguagem racista deste afamado abolicionista. Basta-me citar uma frase de Carvalho para termos em mente o tipo de leitor que se busca alcançar, ou melhor, diria, formar. "O respeito que Nabuco merece nos proíbe qualquer ironia diante da confissão", ou seja, de "como era bom o meu escravo".

Fico com a impressão de que os estudantes de História deveriam se aproximar dos documentos históricos - no caso, o texto de Nabuco -, como se fossem peças sagradas. Antes que os conheçamos, já precisamos venerá-los em todos os seus dizeres, em suma, o velho conselho aos jovens diante dos ancióes com suas cabeças brancas e impolutas. E estamos também proibidos de qualquer ironia, mesmo que o leitor se coloque na pele de um escravo de $\mathrm{Na}$ buco e não goste da idéia de ser amado pelo seu servilismo. Mesmo, enfim, que este leitor seja um brasileiro afro-descendente e

Estudos Afro-Asiáticos, Ano 23, no 1, 2001, pp. 88-97 
não goste de ter seus avós comparados com "animais fiéis" do senhor branco, imagem um tanto forte, aliás, que Carvalho convenientemente não reproduz em seu artigo.

Assim, em vez de desrespeitos e ironias apressadas que só poderiam provir da ignorância do leitor, Carvalho assinala a leitura correta de Nabuco, mesmo que nos deparemos com indícios desairosos para uma figura santificada: "é preciso examiná-la [a confissão de como era bom o meu escravo] dentro do mesmo espírito da análise sociológica de $O$ Abolicionismo"(Carvalho, 2000).

Se o leitor não se sentiu nocauteado pela solenidade destes termos que lhe convidam a fazer uma análise sociológica (haverá aqui a surrada pretensão à neutralidade e imparcialidade?), será possível perceber que o que lhe está sendo proposto é um método correto de ler Nabuco. Ou seja, precisamos nos imbuir do espírito de Nabuco, reproduzir suas palavras sem nenhuma distância cautelar, acreditar nelas como se acredita em uma figura santa. Então, vejamos o que Carvalho nos diz: Nabuco disse,

Os escravos dos engenhos nordestinos não só não se revoltavam contra sua condição, como revelavam gratidão ao senhor, a quem tudo davam. Eles perdoavam a dívida do senhor, anistiando, assim, os países que se construíram com base na escravidão. Sua doçura emprestava até mesmo um reflexo de bondade à opressão de que eram vítimas. (ibidem)

Obviamente, seria impossível imaginar que um historiador como Carvalho desconhecesse que não é verdade que os escravos dos engenhos nordestinos se deixaram explorar e oprimir passivamente ao longo de quase quatro séculos de escravidão. As pesquisas historiográficas avançaram tanto nesse sentido nas últimas três décadas que nos seria impossível ignorar as ações diversas de resistência dos escravos, onde quer que eles tenham vivido no Brasil, e os engenhos decadentes do Nordeste não foram exceção. O próprio Carvalho dá a entender, nas últimas linhas de seu artigo, que a idéia do escravo generoso, isto é, dócil e passivo, seria uma invenção do senhor Nabuco, desejoso de contrabalançar suas emoções com a razão do cidadão Nabuco sobre a perversidade da escravidão. Mas, o artigo de Carvalho termina abruptamente, onde sua análise prometia deixar o Santo de lado para alcançar o homem. Assim, ficamos com as palavras de Nabuco como se elas constituíssem o relato verdadeiro da história da escravidão no Brasil.

Mas a história não é tão simples a ponto de podermos alcançar o relato verdadeiro e definitivo de quaisquer de seus aspectos. Tudo depende do nosso ângulo de visão, no presente, combinado

Estudos Afro-Asiáticos, Ano 23, no 1, 2001, pp. 89-97 
ao ângulo de visão adotado no passado pelos nossos personagens. Assim, o mesmo Nabuco que em fins do século XIX parecia se desmanchar em lágrimas ao rememorar os túmulos dos "animais fiéis" de Massangana, anos antes, no calor dos conflituosos eventos abolicionistas, alimentaria pensamentos menos ternos e afetuosos em relação aos escravos. É verdade que a imagem do escravo como animal é recorrente, mas, desta vez, trata-se de animais infiéis e perigosos: a propaganda abolicionista não deveria, de modo algum, dirigir-se aos escravos para não suscitar entre eles a "[...] vindicta barbara e selvagem de uma população mantida até hoje ao nivel dos animaes e cujas paixões, quebrado o freio do medo, não conheceriam limites no modo de satisfazer-se [...]" (Nabuco, 1883:25).

O exemplo máximo desta vindita dos escravos vinha-lhe de São Domingos, a próspera colônia francesa do Caribe, reduzida a cinzas por uma insurreição de escravos e de onde surgira, em seguida, o primeiro Estado independente afro-americano (1791-1804). Os conselhos de seu pai, senador e presidente do Centro Liberal, dirigidos aos parlamentares conservadores em 1870 , são transcritos por Nabuco de modo a reforçar a mensagem central de seu livro $O$ Abolicionismo: fazer a abolição da escravidão dentro da lei, de modo a salvar a grande propriedade agrícola.

As reformas, por poucas que sejam, valem muito na occasião; não satisfazem depois, ainda que sejam amplas. Não quereis os meios graduaes; pois bem, habeis de ter os meios simultaneos; não quereis as consequencias de uma medida regulada por vós pausadamente, haveis de ter as incertezas da imprevidencia; não quereis ter os inconvenientes economicos por que passaram as Antilhas Inglezas e Francezas, correis o risco de ter os horrores de S. Domingos. (ibidem,:68-9)

Mas, neste ponto, é preciso compreender por que Nabuco parecia tão propenso a definir os escravos como animais, tanto em pensamentos ternos como alarmados a seu respeito. Seria simplesmente porque a escravidão os rebaixaria ao nível irracional dos animais? Ou um outro termo recorrente em seus textos - a palavra raça, nos daria a chave da questão?

Evaldo Cabral de Mello, em seu artigo "Abolicionismo", propõe ao leitor limpar do texto esta incômoda noção que não se coaduna com a imagem abnegada do abolicionista Nabuco. Nada tem a ver a palavra raça com as suas preocupações de redenção dos pobres escravos! Passem por cima desta palavra, esqueçam que ela existe no texto de São Nabuco, pois ele - afirma taxativamente

Estudos Afro-Asiáticos, Ano 23, no 1, 2001, pp. 90-97 
Mello - "nunca embarcou nesta canoa". Carvalho logo vem em seu auxílio e abre seu artigo "Saudade do Escravo" reafirmando a mensagem de Mello: Nabuco nunca embarcou "na canoa furada das teorias raciais". Outros, seus contemporâneos, o fizeram; entre os citados, Sílvio Romero, Euclides da Cunha, Nina Rodrigues. Mas, São Nabuco estaria imune a estas baixezas de seu tempo e pode, portanto, ser lido sem que o leitor corra o risco de ser contaminado pelo racismo importado da Europa, tal como uma flor exótica e pútrida.

O caminho adotado por Mello para livrar Nabuco da suspeita de racismo é pensar na escravidão toda vez que ele deixar escorregar, por um lapso, a palavra raça. O essencial, para Nabuco, seria a organização social, a escravidão, e por isso Nabuco emprega a palavra raça "sem rigor conceitual", "desleixadamente".

É provável que Nabuco se sentisse ultrajado por uma tal interpretação de sua obra; pois como aceitar que todo o seu esforço em incorporar o que havia na época de mais sofisticado para uma análise sociológica - as teorias raciais científicas - pudesse ser taxado como desleixo e falta de rigor conceitual? ${ }^{2}$ Leiamos, portanto, Nabuco, sem querer extirpá-lo de seus termos, sem pretender adaptá-lo ao presentismo daqueles que insistem em negar a existência do racismo no Brasil no passado para, porventura, amenizar as arestas do presente. Para começar, vejamos esta longa citação de Nabuco:

Quando os primeiros Africanos foram importados no Brazil, não pensáram os principaes habitantes - é verdade que se o pensassem, isso não os impediria de fazel-o, porque não tinham o patriotismo Brazileiro - que preparavam para o futuro um povo composto na sua maioria de descendentes de escravos. Ainda hoje muita gente acredita que a introducção de cem ou duzentos mil chins seria um facto sem consequencias ethnicas e sociaes importantes, mesmo depois de cinco ou seis gerações. O principal effeito da escravidão sobre a nossa população foi assim africanizal-a, satural-a de sangue preto, como o principal effeito de qualquer grande empreza de immigração da China seria mongolizal-a, satural-a de sangue amarello.

Chamada para a escravidão, a raça negra, só pelo facto de viver e propagar-se, foi-se tornando um elemento cada vez mais consideravel da população [...]. Foi essa a primeira vingança das victimas. Cada ventre escravo dava ao senhor tres e quatro crias que elle reduzia a dinheiro; essas por sua vez multiplicavam-se, e assim os vicios do sangue Africano acabavam por entrar na circulação geral do paiz. (ibidem:136-7)

Este é apenas um entre outros momentos em que Nabuco relaciona o escravo no Brasil a uma raça humana específica, a raça

Estudos Afro-Asiáticos, Ano 23, no 1, 2001, pp. 91-97 
africana. Outras raças aparecem em seu texto - a raça amarela, ou seja, a raça dos chineses que alguns políticos incautos pretendiam trazer como imigrantes para o Brasil. Ambas têm seus atributos mentais específicos, nada favoráveis, na visão de Nabuco, ao progresso do Brasil. Os africanos têm seus vícios de sangue, corrompem a língua, a religião, os costumes, a família, a sociedade em geral. Enfim, a "africanização" do Brasil só tem deixado à mostra os efeitos nefastos da raça negra, com seu "desenvolvimento mental atrazado", seus "instintos bárbaros", suas "superstiçôes grosseiras" (ibidem:144). Quanto aos chineses, supõe-se que sua raça não seja de efeitos menos nefastos. Nabuco não entra em detalhes, mas diz, peremptoriamente, que "essa onda Chineza" pretendida por alguns apenas viria a "viciar e corromper ainda mais a nossa raça" (ibidem:252-3). Atentemos aqui para esta última menção: "a nossa raça”. Sim, também encontramos no texto de Nabuco a raça à qual ele imagina pertencer, assim como os leitores ilustres aos quais ele se dirige. E qual é "a nossa raça"?

A "nossa raça" é a raça branca, aquela que escraviza a raça africana. Como ele explica, "ninguém pensa em reduzir homens brancos ao captiveiro", pois a escravidão moderna, ao contrário da antiga, repousa sobre a "côr preta" (idem:22). A "nossa raça" é a "raça mais adeantada", a qual infelizmente tem sido "abastardada" pela raça "mais atrazada" devido às facilidades que o cotidiano da escravidão doméstica oferece ao "cruzamento entre Brancos e Negros” (ibidem:144-5). É certo, porém, que caso os africanos não tivessem sido reduzidos à escravidão no Brasil, este mesmo cruzamento entre brancos e negros poderia ter efeitos benéficos para a raça mais atrasada. Sem a escravidão, o cruzamento entre duas raças desiguais em seus atributos mentais teria significado a "gradual elevação" da raça mais atrasada para o nível da mais adiantada.

Contudo, a despeito de suas preocupações humanitárias em relação à situação de vida enfrentada pela raça escravizada no Brasil, Nabuco nunca perdia de vista os interesses da "nossa raça", ou seja, aquela à qual ele supunha pertencer. Se os portugueses tivessem colonizado o Brasil com africanos livres, isto seria, sem dúvida, muito benéfico para a elevação mental da raça negra e o Brasil como um todo "seria uma nação muito mais robusta". Mas, melhor ainda seria se os portugueses não tivessem trazido africanos para o Brasil, contentando-se tão-somente com uma lentíssima colonização do território brasileiro através da imigração de europeus (ibidem::141-2).

Estudos Afro-Asiáticos, Ano 23, no 1, 2001, pp. 92-97 
Em suma, segundo Nabuco, desenhavam-se três alternativas para os portugueses no alvorecer do século XVI: 1) colonizar rapidamente o Brasil com escravos africanos; 2) colonizar o Brasil com africanos livres; 3) colonizar gradualmente o Brasil com imigrantes europeus. As duas primeiras alternativas, como vimos, traziam a inconveniência de introduzir entre a raça adiantada, uma raça atrasada; mas, a segunda alternativa permitiria reverter os efeitos nefastos da raça atrasada sobre a adiantada. Já a terceira alternativa, a ausência total da raça atrasada na "nossa população", permitiria que o Brasil crescesse "sadio, forte e viril, como o Canadá e a Austrália [...]” (idem).

Era a esta terceira alternativa, combinada com a segunda, que se abria o texto de Nabuco. Ou seja, abolir a escravidão, permitindo que doravante o Brasil pudesse ser reconstruído "sobre o trabalho livre e a união das raças na liberdade" (idem:19). E, com isso, atrair um número incessante de imigrantes europeus para o Brasil, o que para Nabuco significava assegurar que os danos causados pelo cruzamento da "nossa raça" com a raça africana pudessem ser revertidos pela atuação miscigenadora e purificadora da raça branca, segundo o vulgo científico de sua época, a raça caucasiana. A imigração européia enquanto "uma corrente de sangue caucásico, vivaz, enérgico e sadio", circulando em meio à população do Brasil, realizaria enfim, a terceira alternativa ignorada pelos portugueses, os quais, em seu açodamento e cobiça, preferiram imprimir esta "nódoa" em sua própria face, a "africanização do Brasil”.

Inútil pretender escapar da análise racializada da sociedade brasileira que nos foi legada por Nabuco. Raça e escravo são termos perfeitamente intercambiáveis em Nabuco. Na sua posição social de proprietário, senhor de escravos e político, ele procurou resolver o impasse da escravidão - afinal, o Brasil era, em meados dos anos 1880, o último país escravista do Continente americano - sem atentar contra a grande propriedade agrícola. Para isso, era preciso reconhecer pragmaticamente que a "raça africana" era uma parte substancial da população do Brasil e que seus interesses, uma vez despertados, poderiam divergir perigosamente dos interesses dos senhores (idem:20). A história pós-emancipacionista das Colônias inglesas e francesas do Caribe e do Sul dos Estados Unidos ofereciam exemplos em profusão de que os ex-escravos se recusavam a se submeter aos interesses da grande propriedade, interpretando a liberdade como trabalho para si próprios e suas famílias. Pior ainda, da perspectiva dos senhores, eram os exemplos vindos

Estudos Afro-Asiáticos, Ano 23, no 1, 2001, pp. 93-97 
do Sul dos Estados Unidos, onde a experiência recente da Reconstrução Radical levantara suspeitas entre os brancos derrotados na Guerra Civil (1861-1865) de que os negros poderiam reconstruir uma nova hierarquia política racial, com os negros no topo e os brancos na base.

Em minha opinião, O Abolicionismo de Nabuco deve ser compreendido de uma dupla perspectiva. Em primeiro lugar, trata-se de um apelo de um proprietário previdente à grande propriedade em geral. Melhor conciliar para não perder; abolir a escravidão dentro da lei e ao mesmo tempo fortalecer a "nossa raça" através de uma corrente massiva de imigrantes europeus. Assegurar, enfim, a paz racial e social, construindo uma maioria branca e garantindo-lhe a continuidade da grande propriedade agrícola capitalista.

Em segundo lugar, temos um livro de intervenção política perfeitamente afinado com a corrente abolicionista internacional de teor liberal, moderada e pragmática que havia se imposto vitoriosamente na Conferência contra a Escravidão, realizada em Paris em 1867. Nesta Conferência, abolicionistas de diversos países deram-se as mãos para derrotar a corrente abolicionista francesa, de teor anarquista, que insistia em cobrar medidas radicais contra o Brasil escravocrata. Uma vez silenciadas as vozes abolicionistas radicais que denunciavam a violência dos senhores brasileiros contra os seus escravos, ganhou força o discurso abolicionista internacional que firmava o Brasil como um paraíso racial, onde a escravidão seria praticada sem a violência observada antes no Sul escravista dos Estados Unidos. Além disso, o Brasil primaria pela ausência de preconceitos de cor contra os africanos e seus descendentes, os quais se integravam facilmente à sociedade uma vez emancipados. ${ }^{5}$

Ao contrário do que afirma Carvalho em seu artigo, sobre a "intuição, fascinante e intrigante, do grande abolicionista a respeito da diferença que haveria entre a escravidão brasileira e a norte-americana”, Nabuco não desenvolveu nenhum pensamento original sobre a suposta ausência de "prevenção de cor" no Brasil. Esta imagem do Brasil paradisíaco em matéria de relações raciais já vinha se desenvolvendo há pelo menos cinco décadas como parte do esforço político do abolicionismo anglo-americano de atacar a escravidão do Sul dos Estados Unidos, representando-a como a escravidão mais violenta do mundo e de todos os tempos. O que importa aqui, portanto, é compreender por que Nabuco aderiu politicamente a esta imagem do paraíso racial brasileiro, presente já de longa data entre os abolicionistas dos Estados Unidos e utilizada

Estudos Afro-Asiáticos, Ano 23, no 1, 2001, pp. 94-97 
como arma contra o radicalismo dos abolicionistas anarquistas em 1867, em Paris. O ex-escravo Luís Gama, outro "grande abolicionista" - Nabuco não diria isso... - certamente não concordaria que em "terra onde rege o branco", o preconceito de cor não seria sentido entre negros.

Enfim, o que quero ressaltar aqui é que Nabuco, assim como qualquer um de nós, passou a vida a fazer escolhas. Ao escolher a imagem do paraíso racial brasileiro legada por uma determinada corrente política abolicionista internacional, Nabuco o fez em detrimento de outra corrente abolicionista, cujas imagens - se tivessem tido ocasião de frutificar - teriam rebaixado o Brasil ao inferno racial usualmente associado aos Estados Unidos. Em suma, se quisermos compreender "o espírito" de sua "análise sociológica" da escravidão, precisamos ultrapassar a tradicional celebração historiográfica em torno de Nabuco, cujas palavras passam por uma descrição isenta e verdadeira da sociedade brasileira do século XIX; com exceção, é claro, daquelas que devem ser suprimidas por se constituírem em incômodas escorregadelas racistas.

Meu intuito aqui foi convidá-los a reler Nabuco, deixando de lado os cânones tradicionalmente associados ao seu nome e revividos há pouco pelos historiadores Evaldo Cabral de Mello e José Murilo de Carvalho. Reler Nabuco significa descanonizá-lo para, então, poder compreender a figura humana dentro dos diálogos e conflitos de seu tempo. Significa também reconhecer fontes importantes do nosso imaginário presente e como elas foram (e são) expurgadas de seus termos mais cruamente racistas pelos intérpretes com poder de mídia para eleger textos clássicos/canônicos. Enfim, meu convite é para relermos Joaquim Nabuco, sem saudades de São Nabuco.

Mas, afinal, quem precisa de São Nabuco? Possivelmente ainda o Brasil que se imagina uma democracia racial e que, agora, nas comemorações dos 500 anos, se encolhe, surpreendido pelo espetáculo não oficial das passeatas de índios e sem-terra. Arcos, flechas e foices, brandidos no horizonte, parecem dizer vitoriosamente, "olhem, apesar de vocês, nós ainda estamos por aqui; e ficaremos".

\section{Notas}

1. Escrevi este artigo embalada por hinos religiosos vindos da Igreja do Largo de Pinheiros, São Paulo, cujo padre parece disposto a nos fazer cristãos-católicos à força, celebrando suas missas pelo alto falante. A coincidência talvez deva me servir de alerta

Estudos Afro-Asiáticos, Ano 23, no 1, 2001, pp. 95-97 


\section{Celia Maria Marinho de Azevedo}

quanto aos perigos de trazer à baila as vidas de santos... Agradeço o convite do Centro Acadêmico de Ciências Humanas - CACH, do IFCH-Unicamp, para apresentar uma primeira versão deste artigo em seu evento “Que 500 Anos são Esses?”, em 19 de abril de 2000 .

2. A concepção do negro enquanto membro de uma raça inferior era usualmente associada à imagem da "fidelidade canina" em tratados teórico-científicos sobre as raças humanas e suas distintas características físicas e mentais. Assim, não é por mero acaso que ao Nabuco ilustrado e cônscio do seu pertencimento à raça superior caucasiana lhe venha à mente a imagem do "animal fiel" nos momentos em que ele se lembra ternamente dos seus queridos escravos já de há muito perdidos. Alguns anos após Nabuco deixar estas páginas memoráveis sobre os escravos/animais fiéis de seu engenho, o leitor da Enciclopédia Britânica encontraria o seguinte verbete sobre "o Negro": "Mentalmente, o negro é inferior ao branco [...] a constituição mental do negro é muito similar à de uma criança, normalmente de natureza cordata e bem-humorada, mas sujeita a repentinos ataques de emoção e paixão [...] mas, em geral, apresenta uma fidelidade canina em sua condição de servo [...]". Ver "The Negro", Encyclopaedia Britannica (1911) apud Jacoby e Glauberman (1995:438-9).

3. Esta análise racializada da sociedade brasileira é recorrente em Nabuco. Ver, por exemplo, "O Erro do Imperador", em que ele define "o nosso povo", isto é, "um povo depés no chão e manga de camisa” (ênfases do autor) como um povo não-branco. Já em "O Eclipse do Abolicionismo", ele lembra ao Imperador D. Pedro II, "representante povoado da raça branca", o seu dever de resgatar a "outra raça” dos sofrimentos da escravidão. Ver, a respeito, Nabuco (1999:24, 46-7).

4. Ver, a respeito, Foner (1988a, 1988b); Holt (1992).

5. Analisei a construção de uma memória do paraíso racial brasileiro pelos abolicionistas dos Estados Unidos, a partir da década de 1830, em Azevedo (1996:151-62). Sobre o conflito entre abolicionistas anarquistas e liberais na Conferência contra a Escravidão, em 1867, em Paris, ver Azevedo (1995:22-6, 90).

6. Ver Gama (1861:34-9). Analisei a presença de abolicionismos com orientaçóes políticas distintas no Brasil, bem como a construção de uma memória do abolicionismo e das relaçôes raciais por Nabuco em Azevedo (1994:5-19). Nabuco demonstra bem pouco apreço por "Luis Gama e outros" que, conforme ele reconhece, já batalhavam pela abolição da escravidão bem antes da lei de 1871. Contudo, Nabuco deixa claro que o verdadeiro abolicionismo começa onde e quando ele próprio começou, isto é, no Parlamento e na década de 1880. Ver Nabuco (1963:196-7). As historiografias da escravidão e da abolição no Brasil têm, de um modo geral, respeitado a cronologia do abolicionismo tal como proposta por Nabuco... Por isso, raramente se pesquisa o abolicionismo antes dos anos 1880 .

\section{Referências Bibliográficas}

AZEVEDO, Celia M. M. de (1987), Onda Negra, Medo Branco: O Negro no Imaginário das Elites, Século XIX. Rio de Janeiro, Paz e Terra.

(1994), "Abolicionismo e Memórias das Relações Raciais". Estudos Afro-Asiáticos, no 26, pp. 5-19.

Estudos Afro-Asiáticos, Ano 23, no 1, 2001, pp. 96-97 
(1995), Abolitionism in the United States and Brazil: A Comparative Perspective. New York, Garland Publishing Inc.

_ (1996), "O Abolicionismo Transatlântico e a Memória do Paraíso Racial Brasileiro". Estudos Afro-Asiáticos, no 30, pp. 151-162.

CARVALHO, José Murilo de. (2000), "Saudade do Escravo”. Folha de S. Paulo, Caderno "Mais", 2/4, p. 21.

FONER, Eric. (1988a), Reconstruction: America's Unfinished Revolution 1863-1877. New York, Harper \& Row.

. (1988b), Nada a Não ser a Liberdade. Rio de Janeiro, Paz e Terra.

GAMA, Luís. (1861), Primeiras Trovas Burlescas (2a ed.). Rio de Janeiro, Typographia de Pinheiro \& Co.

HOLT, Thomas C. (1992). The Problem of Freedom: Race, Labor, and Politics in Jamaica and Britain, 1832-1938. Baltimore, The Johns Hopkins University Press.

JACOBY, Russell e GLAUBERMAN, Naomi (eds.). (1995), The Bell Curve Debate: History, Documents, Opinions. New York, Random House, Inc..

MELLO, Evaldo Cabral de (2000). "Reler O Abolicionismo". Folha de S. Paulo, Caderno "Mais", 27/2, p. 18.

NABUCO, Carolina. (1979), A Vida de Joaquim Nabuco (5a ed.). Rio de Janeiro/Brasília, José Olympio/ INL.

NABUCO, Joaquim. (1883), O Abolicionismo. Londres, Abraham Kindon \& Co. - (1963), Minha Formação. Brasília, Editora da Universidade de Brasília.

_. (1999), A Abolição e a República. Organização e apresentação de Manuel Correia de Andrade. Recife, Editora Universitária da UFPE. 